- improved electronic feedback on the status of data transfer will be provided, so that problems will be identified within 24 hours;

- area health services will provide priority IT support to PHU networks;

- the contractor supporting the NDD software will be on standby to deal with software problems;

- data will be entered by CDSCU staff if any PHU experiences extended difficulties.

These changes to the electronic data flow for notifications of communicable diseases will continue to be used after the Sydney 2000 Olympic and Paralympic Games. The enhancements initiated for the Games will thereby yield benefits for the surveillance and control of communicable diseases in NSW in the longer term.

\section{REFERENCE}

1. NSW Department of Health. Notifiable Diseases Manual. Sydney: NSW Department of Health, 2000. 媐
FIGURE 4

COMMUNICABLE DISEASE DATA FLOW

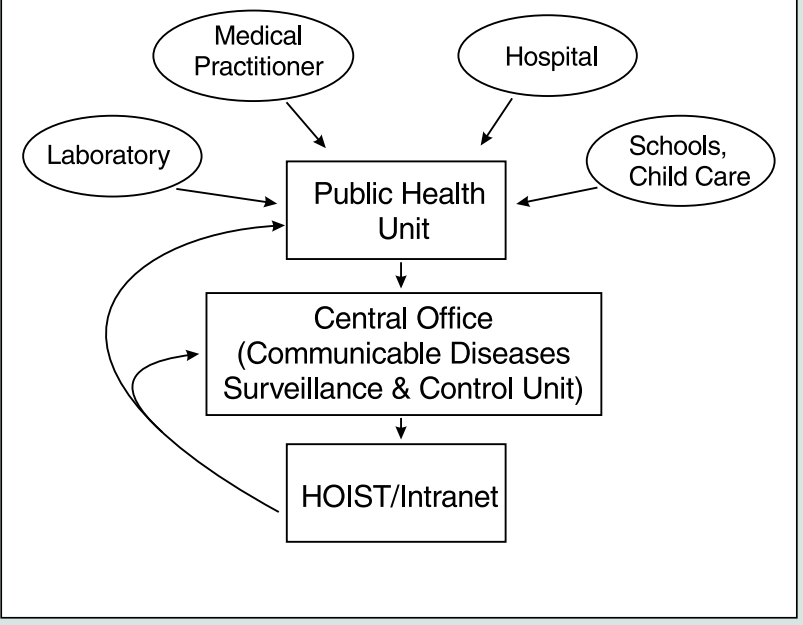

\title{
ENVIRONMENTAL HEALTH PREPARATION FOR THE SYDNEY 2000 OLYMPIC AND PARALYMPIC GAMES
}

\section{Karen Banwell \\ Olympic Planning Unit \\ NSW Department of Health}

Preventing exposure to environmental hazards is essential to protecting the health and safety of the public during an event such as the Sydney 2000 Olympic and Paralympic Games.

Environmental health activities during the Centenary Olympic and Paralympic Games in Atlanta 1996 concentrated on food safety. In addition, special regulations and procedures for solid waste, vector control, swimming pools, recreational waters, temporary food services, tourist accommodation and sewage disposal were enacted for the Games period. ${ }^{1}$

NSW Health has also focused on food safety in its preparations for the Games (see the article by Holroyd et al. on page 151). High priority has also been given to a range of other environmental health issues, particularly preventing Legionnaires' disease. This article outlines NSW Health's preparations for enhancing existing environmental health responsibilities for the Games.

\section{ENVIRONMENTAL HEALTH PLANNING}

Early in its planning for the Games, the Olympic Public Health Planning Committee identified key public health issues for management. These provided a framework for developing the Olympic Environmental Health Operational Plan. This Plan is aimed at identifying partnerships, prioritising activities, identifying media issues and providing guidance for local public health unit operational plans.

The Plan has two main components, aimed at:

- minimising the risk to public health in areas outside of Olympic venues and dedicated Olympic areas

- providing an environmental health presence and inspection services inside Olympic venues and dedicated areas.

The Environmental Health Operational Plan identified a range of activities that were viewed as essential in the protection of public health. These were summarised under the headings of:

- air quality

- water quality

- sanitation

- waste

- vector control

- emergency management

- premises

- standing operating procedures for Olympic venues

- cruise ships (see article by Waples et al. on page 150).

Priority was given to three issues:

- the development of a Legionella plan (outlined below)

- education on preventing Cryptosporidium in pools

- improved public health preparedness for mass gatherings. 


\section{The Legionella Plan}

Although most cases of Legionnaires' disease occur in isolation, recent outbreaks of the disease, including one associated with the Melbourne Aquarium, have attracted international media attention. Minimising the risk of an outbreak of Legionnaires' disease has been a key priority leading up to and during the Games, because large numbers of people will congregate in areas of the city where water cooling systems with cooling towers are located.

Implementation of the Legionella Plan depends on partnerships between public health unit Olympic Coordinators and environmental health officers from local government across metropolitan Sydney. Local government is responsible for maintaining registers of cooling towers. Councils have expanded their inspection regimen of cooling towers and there are specific local plans in preparation for the Games.

Strategies in place to maximise compliance with the cleaning and maintenance provisions for cooling towers, outlined in the NSW Public Health Act 1991, include:

- maintenance of a Geographical Information System (GIS) database of all cooling towers registered with local councils

- registration of all buildings owned by the Commonwealth government with the relevant local council

- review of the Legionella Emergency Management Plan

- inspection of cooling towers in areas of potential risk

- provision of educational material on best management to building owners and operators.

\section{ENVIRONMENTAL HEALTH SERVICES IN OLYMPIC VENUES}

The NSW Department of Health will provide an environmental health presence within Olympic and
Paralympic venues. The key tasks involved are outlined in Environmental Health Standing Procedures for Olympic Venues.

A pre-inspection of each venue will be carried out prior to sporting events commencing. This will involve final inspections of all water cooling systems and checks on provision of adequate waste services within medical centres, provision of sanitation and general safety matters. Routine inspections of waste and sanitation services will be carried out at intervals during the Games.

\section{After the Games}

The Games have provided an excellent opportunity to build environmental health awareness in many sectorsparticularly shipping and building maintenance. Improved liaison between local councils and the NSW Health system will yield ongoing benefits. For the first time, large numbers of environmental health officers from the public health network and local councils are working closely together. The result will be a better understanding of respective roles and responsibilities, and a lasting legacy of networks and associations.

\section{ACKNOWLEDGEMENTS}

I would like to acknowledge the support and leading role played by the public health units, local councils and the Olympic Environmental Health Steering Committee in the development and implementation of this plan.

\section{REFERENCE}

1. Maria Visotina. Health and Medical Services for the Centennial Olympic Games Atlanta Georgia. Internal Report. Sydney: NSW Department of Health, 1996.

\section{INTRODUCING A NSW VESSEL INSPECTION PROGRAM FOR CRUISE SHIPS}

Karen Banwell and Tony Butler

Olympic Planning Unit

NSW Department of Health

Mark Ferson, Steve Hatzi and Paul Paraskevopoulos South Eastern Sydney Public Health Unit

This article outlines the background to the introduction of a Vessel Inspection Program in NSW. The program aims to ensure the health and safety of passengers and crew on cruise ships through a hygiene inspection regimen.
During the Sydney 2000 Olympic and Paralympic Games, nine cruise ships and two tall ships will be moored in Sydney Harbour for just over three weeks. Eight ships will serve as floating hotels for Olympic sponsors and their guests, and one will serve as accommodation for international broadcasting personnel. The floating hotels will provide approximately 6,000 beds at any one time with an overall throughput of around 32,000 people. The average length of stay is expected to be three to four days.

Outbreaks of disease on cruise ships are well documented. ${ }^{1-3}$ Gastroenteritis, Legionnaires' disease, 